\title{
CORRESPONDENCE
}

We welcome letters to the Editor concerning articles which have recently been published. Such letters will be subject to the usual stages of selection and editing; where appropriate the authors of the original article will be offered the opportunity to reply.

Letters should normally be under $\mathbf{5 0 0}$ words in length, double-spaced throughout, signed by all authors and fully referenced. The edited version will be returned for approval before publication.

\section{GLOVE PENETRATION DURING HIP ARTHROPLASTY}

Sir,

In the November 1993 issue Wright, Moran and Briggs report a $67 \%$ rate of glove penetration during hip arthroplasties $(1993 ; 75$ B:918-20). This could surely be reduced by a return to some form of 'no-touch technique' which would protect the surgeon and also reduce wound infection. The risk to the operator of hepatitis $B$ and HIV infection might also be decreased.

A. L. MACAFEE, MD, FRCS

142 Warren Road

Donaghadee

County Down, UK.

Wright KU, Moran CG, Briggs PJ. Glove perforation during hip arthroplasty: a randomised prospective study of a new taperpoint needle. J Bone Joint Surg [Br] 1993; 75-B:918-20.

\section{SUGIOKA OSTEOTOMY FOR AVASCULAR NECROSIS}

Sir,

Dean and Cabanela (1993;75-B:597-601) consider that ethnic variations in anatomy may be the cause of differing results after Sugioka's osteotomy for avascular necrosis. I have operated on patients from Europe, Africa and Asia and do not believe that ethnic origin is important.

This osteotomy, as stressed by the originator, is also a delicate vascular procedure involving careful division of some fibres of quadratus femoris, detachment of the external obturator muscle and preservation of the posterior vessels of the femoral neck. Dean and Cabanela do not mention this.

They also differed in their management of the capsule. Sugioka advises that this be left open and not repaired. A third difference was in after-care. I believe that capsular repair and much too early rehabilitation account for some of the poor results reported by Dean and Cabanela. Other details may also be important. A lateral incision does not give the best exposure of the vascular pedicle: Sugioka uses a modified Ollier incision. Fixation with a bulky Richards screw is not the best method.

In addition it should be recorded that Eyb and Kotz (1987) reported 59\% good or excellent results in Caucasians. Perhaps the

(01994 British Editorial Society of Bone and Joint Surgery 0301-620X/94/3802 \$2.00

J Bone Joint Surg [Br] 1994; 76-B:505-8. 'ethnic difference' is keeping patients in bed for six weeks, as advised by Sugioka; capsular repair and early mobilisation are not the answer.

The Sugioka osteotomy is a delicate procedure (with a long learning curve), but I believe it to be a good operation with promising results.

\section{J. W. M. GARDENIERS, MD \\ Institute of Orthopaedics \\ University Hospital \\ Nijmegen, The Netherlands.}

Dean MT, Cabanela ME. Transtrochanteric anterior rotational osteotomy for avascular necrosis of the femoral head: long-term results. $J$ Bone Joint Surg [Br] 1993; 75-B:597-601.

Eyb R, Kotz R. The transtrochanteric anterior rotational osteotomy of Sugioka: early and late results in idiopathic aseptic femoral head necrosis. Arch Orthop Trauma Surg 1987; 106:161-7.

Authors' reply:

Sir,

We agree with Dr Gardeniers that the Sugioka osteotomy is a very difficult procedure. We did not undertake it until we had seen a videotape of Dr Sugioka performing the operation and tried it on cadavers half-a-dozen times. Our description of the technique included only the salient points, but we always tried to respect the posterior neck arteries. As mentioned in our discussion, however, we observed that anterior rotation of the femoral head stretched the quadratus femoris in every case: this stretching cannot be good for the blood supply.

Capsular reconstruction after anterior rotation of the femoral head is impossible: we merely placed a few sutures in that part of the capsule that can be approximated, but tension was never produced.

We chose a Richards hip screw and plate fixation since, for our postoperative regime, two wood screws would not be sufficient, as also noted by Eyb and Kotz (1987).

We found that the lateral incision was certainly more than adequate to expose carefully the entire capsule and the vascular pedicle after trochanteric osteotomy; it provides better exposure than most other approaches to the hip.

We do not question that Dr Sugioka can obtain the results which he reported with his procedure; but his results could not be reproduced in either the North American continent or in Europe, and even in Japan other surgeons have not been able to duplicate his results.

We believe that in his environment, with his skills, and operating on his group of patients, Dr Sugioka can achieve results that are probably not within the reach of others. The ultimate value of an operation is when it can be performed with similar results by a large number of surgeons of adequate skills. This has not been so and may be the reason for its lost popularity among hip surgeons.

M. E. CABANELA, MD

M. T. DEAN, MD

Mayo Clinic and Mayo Foundation

Rochester

Minnesota, USA

Eyb R, Kotz R. The transtrochanteric anterior rotational osteotomy of Sugioka: early and late results in idiopathic aseptic femoral head necrosis. Arch Orthop Trauma Surg 1987; 106:161-7. 